Article

\title{
AlGaN Ultraviolet Metal-Semiconductor-Metal Photodetectors with Reduced Graphene Oxide Contacts
}

\author{
Bhishma Pandit and Jaehee Cho * (D) \\ School of Semiconductor and Chemical Engineering, Chonbuk National University, Jeonju 54896, Korea; \\ bhishmapandit2046@gmail.com \\ * Correspondence: jcho@chonbuk.ac.kr
}

Received: 24 September 2018; Accepted: 27 October 2018; Published: 1 November 2018

\begin{abstract}
AlGaN semiconductors are promising materials in the field of ultraviolet (UV) detection. We fabricated AlGaN/GaN UV metal-semiconductor-metal (MSM) photodiodes with two back-to-back interdigitated finger electrodes comprising reduced graphene oxide (rGO). The rGO showed high transparency below the wavelength of $380 \mathrm{~nm}$, which is necessary for a visible-blind photodetector, and showed outstanding Schottky behavior on AlGaN. As the photocurrent, dark current, photoresponsivity, detectivity, and cut-off wavelength were investigated with the $\mathrm{rGO} / \mathrm{AlGaN}$ MSM photodiodes with various $\mathrm{Al}$ mole fractions, systematic variations in the device characteristics with the $\mathrm{Al}$ mole fraction were confirmed, proving the potential utility of the device architecture combining two-dimensional materials, rGO, and nitride semiconductors.
\end{abstract}

Keywords: ultraviolet photodiode; AlGaN; graphene oxide; MSM photodiode; visible-blind

\section{Introduction}

The III-nitride semiconductors and alloys thereof have been studied extensively because of their wide and direct bandgaps, high breakdown voltages, high mechanical and chemical stabilities, and low reverse leakage currents. These promising properties have inspired the use of III-nitride semiconductors for many applications such as light-emitting diodes, laser diodes, photodetectors, high electron mobility transistors, field-effect transistors, Schottky diodes, and solar cells [1-5]. Among these applications, ultraviolet (UV) photodetectors that are usable in visible- to solar-blind conditions have drawn significant attention for use in missile plume detection, flame engine sensors, ozone layer monitoring, and secure intersatellite communication systems [6,7]. With a bandgap between those of $\mathrm{GaN}(3.4 \mathrm{eV})$ and $\mathrm{AlN}(6.2 \mathrm{eV})$ [8], AlGaN can be used in both visible- and solar-blind UV photodetectors without bulky filter systems or heavy cooling systems such as those required for Si-based photodetectors, thus reducing the footprint and the production cost of the devices [7]. Regarding the photodetector device architecture, the easy and cost-effective fabrication of metal-semiconductor-metal (MSM) photodiodes with two interdigitated Schottky electrode contacts on their planar semiconductor surfaces has attracted significant attention. Such devices present low dark currents, low noise, high response speeds, and no doped layers $[9,10]$.

Another important factor of planar UV MSM photodiodes is the transparent conducting electrode [11]. The transparency of existing metals and metal oxides declines sharply with decreasing illumination wavelength [12]. Therefore, high transparency in the UV spectral region, high material conductivity, and linear Ohmic contact properties are essential for electrodes in UV photodetectors [7]. Graphene oxide (GO), a derivative of graphene, possesses significant potential as a conductive electrode material with UV transparency [13]. GO can be fabricated via inexpensive and facile 
processes while retaining graphene's properties. Furthermore, by adding thermal or chemical reduction processing [14,15], so-called reduced GO (rGO) can be obtained, which presents variable optical and electrical properties depending on the degree of the oxygen functional groups contained on the basal plane of the rGO. Recently, Zhu et al. and Li et al. demonstrated the potential of rGO electrodes in the Si photodiodes [16,17]. Pandit et al. studied rGO Schottky contacts on a GaN layer, presenting the dependency of the Schottky barrier height on the GO reduction temperature [18]. Hence, the combination of AlGaN and GO-based materials for UV-enhanced optical sensors seems to be an interesting and attractive topic for exploration. An rGO/AlGaN-based photodiode may provide an enhanced photo-to-dark current ratio and tunable cut-off wavelength depending on the $\mathrm{Al}$ mole fraction. Here, we investigated $\mathrm{rGO} / \mathrm{Al}_{x} \mathrm{Ga}_{1-\mathrm{x}} \mathrm{N}$ MSM photodiodes with various $\mathrm{Al}$ mole fractions, $x$. Measurements of the dark current, photocurrent, and photoresponsivity of the fabricated devices showed systematic correlations of these properties with the $\mathrm{Al}$ mole fraction in the AlGaN layer.

\section{Materials and Methods}

Three $\mathrm{Al}_{\mathrm{x}} \mathrm{Ga}_{1-\mathrm{x}} \mathrm{N} / \mathrm{GaN}(300 \mathrm{~nm} / 1.5 \mu \mathrm{m})$ samples with different $\mathrm{Al}$ mole fractions were grown on (0001) sapphire substrates by metalorganic chemical vapor deposition. Before device fabrication, the samples were cleaned by ultrasonication in acetone, methanol, isopropyl alcohol, and deionized (DI) water. Then, the samples were cleaned with buffered oxide etchant (BOE), piranha solution $\left(\mathrm{H}_{2} \mathrm{SO}_{4}: \mathrm{H}_{2} \mathrm{O}_{2}\right)$, and, lastly, DI water. As shown in Figure 1, for device fabrication, first, the aqueous $\mathrm{GO}$ solution prepared by the modified Hummers method [19] is sprayed over the sample, which is laid on a hot plate with a temperature of $180^{\circ} \mathrm{C}$. The GO/AlGaN/GaN samples are quickly transferred to a furnace chamber for the thermal reduction of the GO films by heating at $800{ }^{\circ} \mathrm{C}$ for $10 \mathrm{~min}$. Next, a probing metal pad of $\mathrm{Ti} / \mathrm{Au}$ is deposited by an electron beam (E-beam) evaporation system, assisted by a lift-off process. An etch mask of $100 \mathrm{~nm}$ thick $\mathrm{SiO}_{2}$ for $\mathrm{rGO}$ etching is deposited by E-beam evaporation and patterned as an interdigitated shape by conventional photolithographic techniques and $\mathrm{BOE}$ treatment. Finally, the $\mathrm{rGO}$ film is etched out by $\mathrm{O}_{2}$ plasma treatment before the remaining $\mathrm{SiO}_{2}$ is dissolved using BOE.

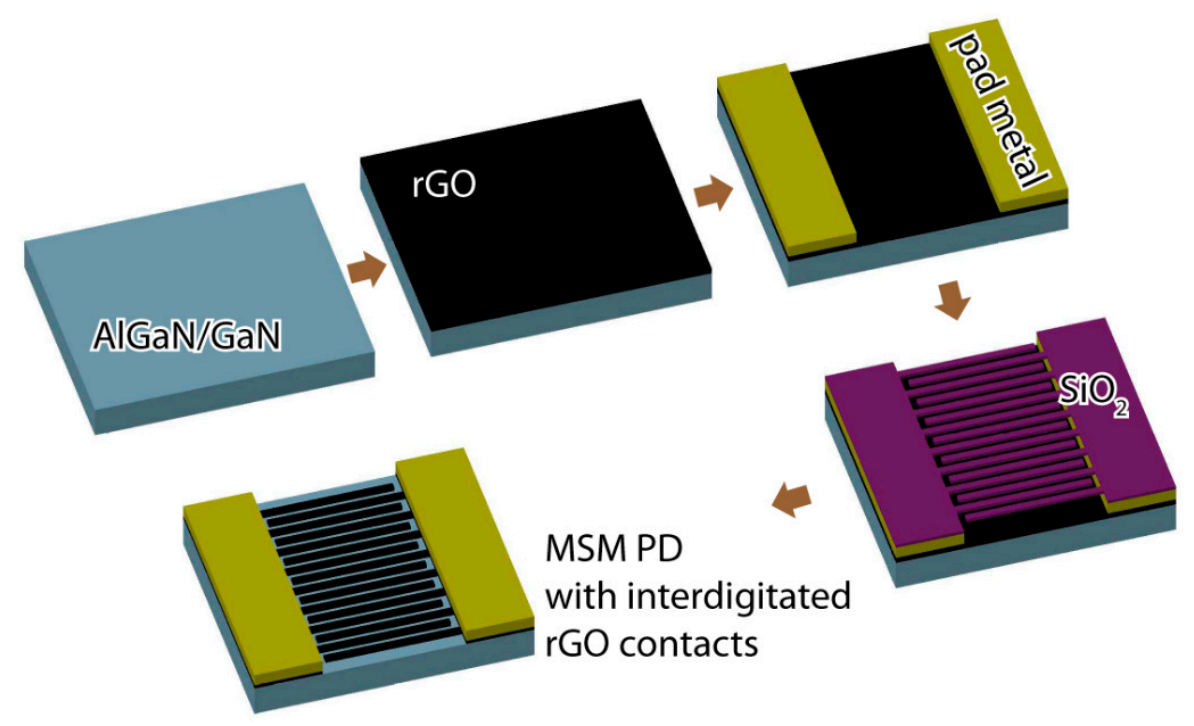

Figure 1. Schematic fabrication process for reduced graphene oxide (rGO)/AlGaN/GaN metal-semiconductor-metal (MSM) photodiodes.

High-resolution X-ray diffraction (XRD) measurement was performed to determine the lattice parameters of the AlGaN films and thus obtain the $\mathrm{Al}$ mole fractions. The measurements of the photodetection properties were performed using a dark-room probe station system equipped with a 
Keithley 2400 source meter, a Bentham SSM150Xe switching monochromator, and a calibrated optical power sensor.

\section{Results and Discussion}

Figure 2 shows the high-resolution XRD measurements of the three AlGaN/GaN samples that were used to obtain the accurate $\mathrm{Al}$ mole fraction. Peaks corresponding to the lattice parameters of $\mathrm{GaN}$ and $\mathrm{AlGaN}$ are clearly shown in the figure. An enlarged view of the AlGaN peaks is shown in the inset of Figure 2. The lattice parameters $(c)$ of the samples were calculated by the Bragg relation, $c=\frac{\lambda l}{2 \sin \theta_{B}}$, where $\lambda$ is the wavelength of the $X$-ray radiation used for the measurement, $\theta_{\mathrm{B}}$ is the Bragg angle, and $l$ is the Miller index. The $\mathrm{Al}$ mole fractions $(x)$ of the samples were then calculated by Vegard's rule: $C_{A l G a N}(x)=x C_{A l N}+(1-x) C_{G a N}-\delta_{c} x(1-x)$, where $C_{A l N}(4.9792 \AA)$ and $C_{G a N}(5.1855 \AA)$ are the bulk lattice constants of AlN and GaN, respectively, and $\delta_{\mathrm{c}}$ is the bowing parameter available from previous studies [20-22]. The Al mole fractions of the three samples were thus confirmed as $9.5 \%$, $13.4 \%$, and $17.9 \%$ (henceforth given in decimal form as $0.095,0.134$, and 0.179 , respectively).

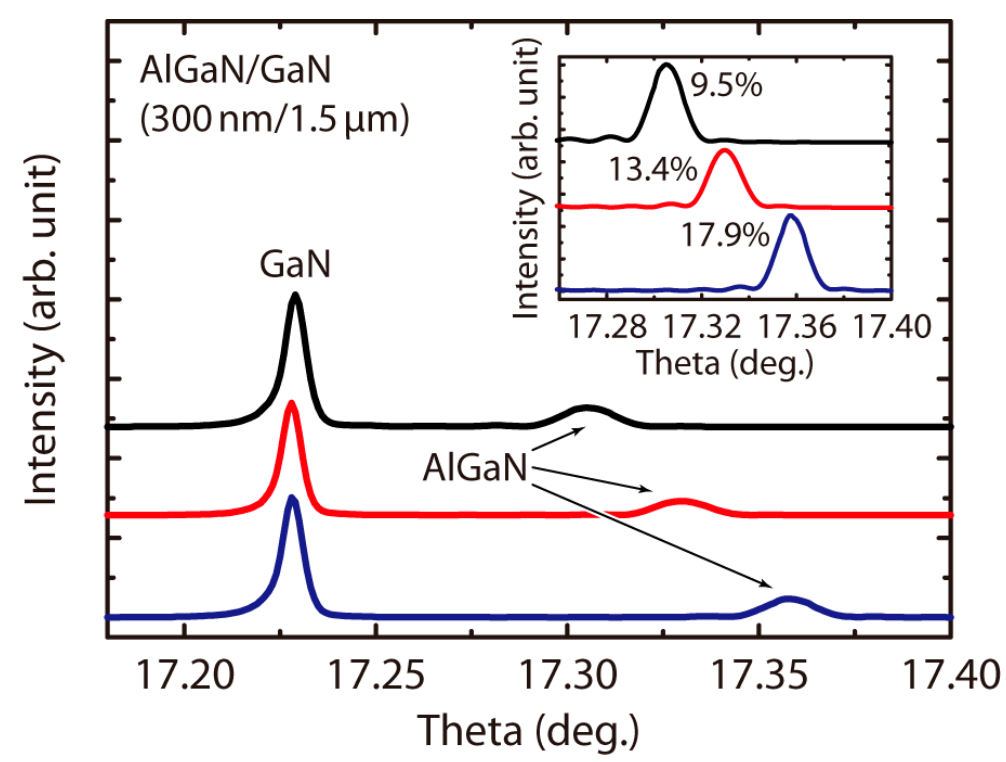

Figure 2. High-resolution XRD measurements of the (0002) planes of AlGaN samples with various $\mathrm{Al}$ mole fractions (inset: enlarged view of the AlGaN peaks).

The GO film shows a very high transmittance over a broad wavelength range, as shown in Figure 3. A slight decrease in transmittance occurs after thermal reduction at $800{ }^{\circ} \mathrm{C}$, and a gradual decrease occurs as the wavelength decreases from $350 \mathrm{~nm}$, which is well matched with the previous report in the literature [23]. Regardless, the transmittances of GO and rGO are $>90 \%$ even for wavelengths $<300 \mathrm{~nm}$. The Raman spectral investigation of the GO film on the AlGaN/GaN substrate showed clearly the primary in-plane vibrational mode of $s p^{2}$-bonded carbon atoms ( $G$ peak) and the defect-induced breathing mode (D peak) [23]. The samples showed $I_{\mathrm{D}} / I_{\mathrm{G}}$ peak intensity ratios of $<0.8$, indicating that the GO layers were successfully formed on the substrates and that defect generation was well suppressed, even during the reduction process. In addition, the sheet resistance of rGO in our study was in the range of $6 \times 10^{3} \Omega / \mathrm{sq}$ [24]. 


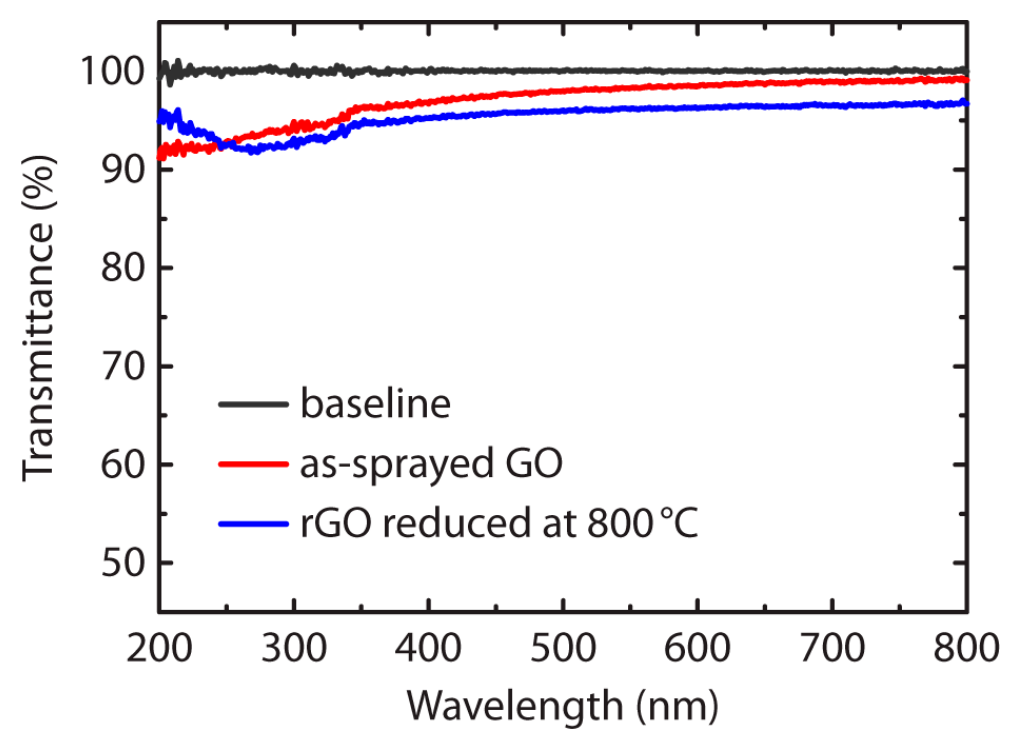

Figure 3. Transmittance spectra of the as-sprayed GO and rGO reduced at $800{ }^{\circ} \mathrm{C}$.

Figure 4 shows the current-voltage $(I-V)$ characteristics of the rGO/AlGaN MSM photodiodes under dark and under illumination at $330 \mathrm{~nm}$. The measurements are done on MSM photodiodes (the total area of $350 \times 450 \mu \mathrm{m}^{2}$ ) with the finger length of $200 \mu \mathrm{m}$, width of $10 \mu \mathrm{m}$, and spacing of $10 \mu \mathrm{m}$. Noise-like dark currents of less than $10 \mathrm{pA}$ are measured, indicating that the dark current is below the measurement limit of our measurement system. Under the 330-nm illumination and the bias voltage of $-5.5 \mathrm{~V}$, the photocurrent increases to $24 \mathrm{nA}, 58 \mathrm{nA}$, and $70 \mathrm{nA}$ for the samples with the $\mathrm{Al}$ mole fractions of $0.179,0.134$, and 0.095 , respectively. The increase of more than three orders of magnitude between the dark current and photocurrent implies a high photo/dark current contrast ratio of the devices. Slight increases in photocurrent with the increase of bias are observed in Figure 4 . When defects in the active layer are involved, the trapping of photoexcited carriers might be influenced by the induced bias. The photocurrent under illumination is lower for samples with higher Al mole fractions, namely, in samples with higher energy bandgaps, which is caused by the lower excited carrier concentrations in the samples with higher $\mathrm{Al}$ mole fractions.

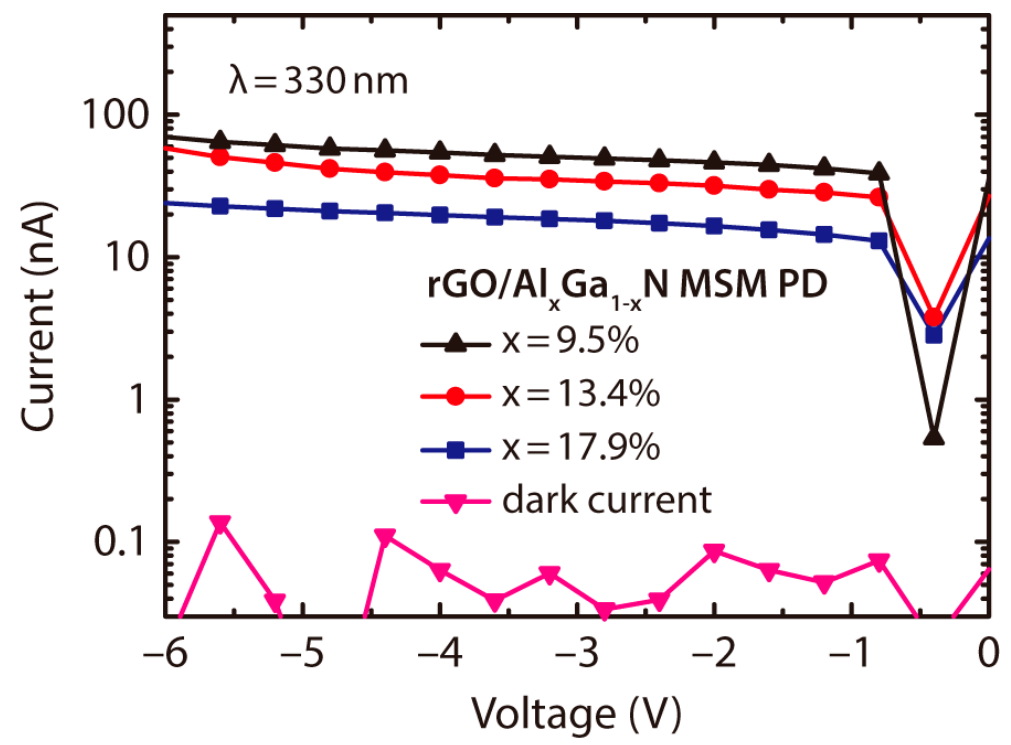

Figure 4. Current-voltage $(I-V)$ characteristics of the rGO/AlGaN MSM photodiodes under dark and under $330 \mathrm{~nm}$ of illumination. 
Figure 5 shows the spectral photoresponses of the samples with three different $\mathrm{Al}$ mole fractions from $300 \mathrm{~nm}$ to $410 \mathrm{~nm}$. The spectral photoresponsivity $(R)$ is calculated with the ratio of the measured output current for a given input optical power as follows [25]:

$$
R=\left(I_{\text {photo }}-I_{\text {dark }}\right) / P_{\text {inc }}
$$

where $I_{\text {photo }}$ is the photocurrent, $I_{\text {dark }}$ is the dark current, and $P_{i n c}$ is the incident optical power. The peak in photoresponsivity is shifted to lower wavelengths (i.e., higher energies) for the $\mathrm{rGO} / \mathrm{AlGaN}$ samples with higher Al mole fractions. The samples show the peak photoresponses of $0.176,0.143$, and $0.111 \mathrm{~A} / \mathrm{W}$ at the wavelengths of $335 \mathrm{~nm}, 325 \mathrm{~nm}$, and $315 \mathrm{~nm}$, respectively. Note that the difference in the peak wavelengths can be associated with the difference in the energy bandgaps of $\mathrm{Al}_{x} \mathrm{Ga}_{1-x} \mathrm{~N}$. The energy bandgap of $\mathrm{AlGaN}$ can be calculated by linear interpolation between the theoretical bandgap values of $\mathrm{GaN}(3.43 \mathrm{eV})$ and $\mathrm{AlN}(6.2 \mathrm{eV})$ [26,27]. Energy bandgaps of $3.69 \mathrm{eV}, 3.8 \mathrm{eV}$, and $3.93 \mathrm{eV}$ are obtained for the samples with $x=0.095,0.134$, and 0.179 , respectively. These values show high correspondence with the peak photoresponsivity wavelengths in Figure 5. The photoresponsivity curves show gradual decreases for further decreasing wavelengths, which is because the photoresponsivity is proportional to the wavelength [5]. All of the experimental results in Figure 5 agree with the theoretical prediction that is expected for the AlGaN UV MSM photodiodes with various Al mole fractions. Small kinks (only visible in a logarithmic-scale plot of Figure 5) in the photoresponsivity curves were also observed near the wavelengths corresponding to the energy bandgap of $\mathrm{GaN}$, which is possibly because of absorption by the underlying $\mathrm{GaN}$ layer, as in the previous report by Kumar et al. with a graphene/AlGaN Schottky diode [28]. As another figure of merit of photodetectors, the detectivity $\left(D^{*}\right)$ shows how much minimum signal can be detected by the photodetector. The detectivity is calculated by using the simplified equation [29]:

$$
D \sim \frac{A^{\frac{1}{2}} R}{\left(2 q I_{\text {dark }}\right)^{\frac{1}{2}}}
$$

where $A$ is the junction area and $q$ is the elementary charge. At the peaks in photoresponsivity, the MSM photodiodes with the $\mathrm{Al}$ mole fractions of $0.095,0.134$, and 0.179 showed the detectivity of $3.9 \times 10^{12}$, $3.17 \times 10^{12}$, and $2.46 \times 10^{12} \mathrm{cmHz}^{1 / 2} \mathrm{~W}^{-1}$, respectively, which are values that are comparable to the literature [29].

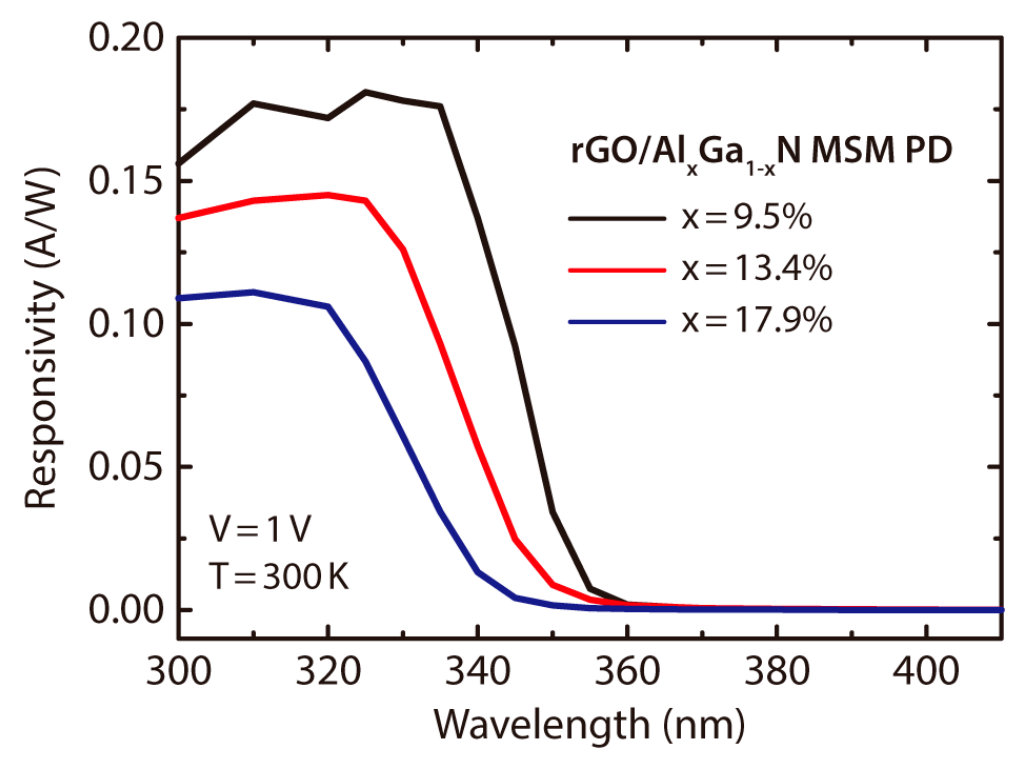

Figure 5. Spectral photoresponses of the $\mathrm{rGO} / \mathrm{AlGaN}$ MSM photodiodes with various $\mathrm{Al}$ mole fractions. 


\section{Conclusions}

In summary, we successfully fabricated and analyzed rGO/AlGaN MSM photodiodes. After a facile fabrication of highly transparent rGO layers, excellent rectifying properties were obtained from the $\mathrm{rGO} / \mathrm{AlGaN}$ MSM structures. When the photoresponsivity was investigated along with the various $\mathrm{Al}$ mole fractions, high photo/dark current ratios and sharp cut-off wavelengths were observed, which were systematically associated with the energy bandgaps of the three different AlGaN samples with Al mole fractions $x=0.95,0.134$, and 0.179 . The results suggested that the $\mathrm{rGO}$ as a transparent Schottky electrode has potential applicability for visible-blind optical sensors when combined with AlGaN semiconductors.

Author Contributions: Original draft preparation with experiment and analysis, B.P.; Supervision and writing-review, J.C.

Funding: This research was funded by the basic science research program through the National Research Foundation (NRF) of Korea funded by the Ministry of Education (No. 2017R1D1A1A09000684) and by the research funds of Chonbuk National University in 2018.

Conflicts of Interest: The authors declare no conflict of interest.

\section{References}

1. Khan, A.; Balalrishnan, K.; Katona, T. Ultraviolet light-emitting diodes based on group three nitrides. Nat. Photonics 2008, 2, 77-84. [CrossRef]

2. Khan, A.M.; Shatalov, M.; Maruska, H.P.; Wang, H.M.; Kuokstis, E. III-Nitride UV Device. Jpn. J. Appl. Phys. 2005, 44, 7191-7206. [CrossRef]

3. Mishra, U.K.; Parikh, P.; Wu, Y.F. AlGaN/GaN HEMTs-An Overview of Device Operation and Applications. IEEE Trans. Electron. Devices 2002, 90, 1022-1031. [CrossRef]

4. Sang, L.; Liao, M.; Sumiya, M.A. Comprehensive Review of Semiconductor Ultraviolet Photodetectors: From Thin Film to One-Dimensional Nanostructures. Sensor 2013, 13, 10482-10518. [CrossRef] [PubMed]

5. Monroy, E.; Omnès, F.; Calle, F. Wide-bandgap semiconductor ultraviolet photodetectors. Semicond. Sci. Technol. 2003, 18, R33-R51. [CrossRef]

6. Schreiber, P.; Dang, T.; Pickenpaugh, T.; Smith, G.; Gehred, P.; Litton, P. Solar blind UV region and UV detector development objectives. Proc. SPIE 1999, 3629, 230-248.

7. Razeghi, M.; Rogalski, A. Semiconductor ultraviolet detectors. J. Appl. Phys. 1996, 79, 7433-7473. [CrossRef]

8. Walker, D.; Zhang, X.; Saxler, A.; Kung, P.; Xu, J.; Razeghi, M. $\mathrm{Al}_{\mathrm{x}} \mathrm{Ga}_{1-\mathrm{x}} \mathrm{N}(0 \leq \mathrm{x} \leq 1)$ ultraviolet photodetectors grown on sapphire by metal-organic chemical-vapor deposition. Appl. Phys. Lett. 1997, 70, 949-951. [CrossRef]

9. Carrano, J.C.; Grudowski, P.A.; Eiting, C.J.; Dupuis, R.D.; Campbell, J.C. Very low dark current metal-semiconductor-metal ultraviolet photodetectors fabricated on single-crystal GaN epitaxial layers. Appl. Phys. Lett. 1997, 70, 1992-1994. [CrossRef]

10. Qi, L.; Mok, K.R.C.; Aminian, M.; Charbon, E.; Nanver, L.K. UV-sensitive low dark-count pureB single-photon avalanche diode. IEEE Trans. Electron. Devices 2014, 61, 3768-3774. [CrossRef]

11. Berger, P.R. Metal-semiconductor-metal photodetectors. Proc. SPIE 2001, 4285, 198-207.

12. Bonaccorso, F.; Sun, Z.; Hasan, T.; Ferrari, A.C. Graphene photonics and optoelectronics. Nat. Photonics 2010, 4, 611-622. [CrossRef]

13. Becerril, H.A.; Mao, J.; Liu, Z.; Stoltenberg, R.M.; Bao, Z.; Chen, Y. Evaluation of solution-processed reduced graphene oxide films as transparent conductors. ACS Nano 2008, 2, 463-470. [CrossRef] [PubMed]

14. Pei, S.; Cheng, H.M. The reduction of graphene oxide. Carbon 2012, 50, 3210-3228. [CrossRef]

15. Tu, N.D.K.; Choi, J.; Park, C.R.; Kim, H. Remarkable Conversion between n- and p-Type Reduced Graphene Oxide on Varying the Thermal Annealing Temperature. Chem. Mater. 2015, 27, 7362-7369. [CrossRef]

16. Zhu, M.; Li, X.; Guo, Y.; Li, X.; Sun, P.; Zang, X.; Wang, K.; Zhong, M.; Wu, D.; Zhu, H. Vertical junction photodetectors based on reduced graphene oxide/silicon Schottky diodes. Nanoscale 2014, 6, 4909-4914. [CrossRef] [PubMed] 
17. Li, G.; Liu, L.; Wu, G.; Chen, W.; Qin, S.; Wang, Y.; Zhang, T. Self-Powered UV-Near Infrared Photodetector Based on Reduced Graphene Oxide/n-Si Vertical Heterojunction. Small 2016, 12, 5019-5026. [CrossRef] [PubMed]

18. Pandit, B.; Cho, J. Metal-semiconductor-metal ultraviolet photodiodes based on reduced graphene oxide/GaN Schottky contacts. Thin Solid Films 2018, 660, 824-827. [CrossRef]

19. Hummers, W.S., Jr.; Offeman, R.E. Preparation of Graphitic Oxide. J. Am. Chem. Soc. 1958, 80, 1339. [CrossRef]

20. Vegard, L. Die konstitution der mischkristalle und die raumfüllung der atome. Z. Phys. 1921, 5, 17-26. [CrossRef]

21. Liou, B.T.; Yen, S.H.; Kuob, Y.K. Vegard's law deviation in band gaps and bowing parameters of the wurtzite III-nitride ternary alloys. Proc. SPIE 2005, 5628, 296-305.

22. Mahata, M.K.; Ghosh, S.; Jana, S.K.; Chakraborty, A.; Bag, A.; Mukhopadhyay, P.; Kumar, R.; Biswas, D. Comprehensive strain and band gap analysis of PA-MBE grown AlGaN/GaN heterostructures on sapphire with ultrathin buffer. AIP Adv. 2014, 4, 117120. [CrossRef]

23. Pandit, B.; Jo, C.H.; Joo, K.S.; Cho, J. Changes in physical properties of graphene oxide with thermal reduction. J. Korean Phys. Soc. 2017, 71, 156-160. [CrossRef]

24. Ryu, B.D.; Hyung, J.H.; Han, M.; Kim, G.S.; Han, N.; Ko, K.B.; Kang, K.K.; Cuong, T.V.; Hong, C.H. Long-term stability of Si-organic hybrid solar cells with a thermally tunable graphene oxide platform. RSC Adv. 2016, 6, 73242-73250. [CrossRef]

25. Ravikiran, L.; Radhakrishnan, K.; Dharmarasu, N.; Agrawal, M.; Wang, Z.; Bruno, A.; Soci, C.; Lihuang, T.; Ang, K.S. GaN schottky metal-semiconductor-metal UV photodetectors on Si (111) grown by ammonia-MBE. IEEE Sens. J. 2017, 17, 72-77. [CrossRef]

26. Wickenden, D.K.; Bargeron, C.B.; Bryden, W.A.; Miragliotta, J.; Christenmacher, T. High quality self-nucleated $\mathrm{Al}_{\mathrm{x}} \mathrm{Ga}_{1-\mathrm{x}} \mathrm{N}$ layers on (00.1) sapphire by low-pressure metalorganic chemical vapor deposition. Appl. Phys. Lett. 1994, 65, 2024-2026. [CrossRef]

27. Ochalski, T.J.; Gil, B.; Lefebvre, P.; Grandjean, N.; Leroux, M.; Massies, J.; Nakamura, S.; Morkoç, H. Photoreflectance investigations of the bowing parameter in AlGaN alloys lattice-matched to GaN. Appl. Phys. Lett. 1999, 74, 3353-3355. [CrossRef]

28. Kumar, M.; Jenong, H.; Polat, K.; Okyay, A.K.; Lee, D. Fabrication and characterization of graphene/AlGaN/GaN ultraviolet Schottky photodetector. J. Phys. D Appl. Phys. 2016, 49, 275105. [CrossRef]

29. Xu, K.; Xu, C.; Xie, Y.; Deng, J.; Zhu, Y.; Guo, W.; Xun, M.; Teo, K.B.K.; Chen, H.; Sun, J. Graphene GaN-based schottky ultraviolet detectors. IEEE Trans. Electron. Devices 2015, 62, 2802-2808. [CrossRef] 